\title{
IMPACT OF SECONDARY SOIL TILLAGE TECHNOLOGY ON SOIL PARTICLE DISPLACEMENT ON SLOPING FIELDS IN CENTRAL BOHEMIA REGION
}

\author{
Josef Hula, Petr Novak, Jitka Kumhalova \\ Czech University of Life Sciences Prague \\ hula@tf.czu.cz
}

\begin{abstract}
One of the main factors of land degradation, not only in the Czech Republic, is soil erosion. One relatively new erosion factor is tillage erosion. More than $70 \%$ of agricultural land (about 2 million ha) is used as cultivated in the Czech Republic. Effect of tillage erosion on the overall land degradation is often underestimated. Wrong way of implementation of soil tillage has a clear impact on land degradation. Relatively little expert studies have been devoted to this phenomenon. A field experiment was carried out for the purposes of measuring the displacement of soil particles during secondary tillage. The field experiment was situated in Nesperská Lhota location. Sloping land with light Cambisol was used for the measurement. Secondary tillage (seedbed preparation) was the evaluated technology. Metallic tracers (cube of aluminum - edge $12 \mathrm{~mm}$ ) were used as an indicator of particle displacement. The influence of slope on the particle displacement was evaluated in the experiment. There were placed 30 tracers to the soil surface in one row and their position was determined. The field experiments had three options: to move the machine on a plane, machine movement against the slope and movement of the machine along the slope. Position of individual tracers relative to the original location was determined after the combinator Lemken passing. Metal detectors were used to determine the position of the metallic tracers after soil tillage. Travel distance of all tracers was deducted from their original locations. Their displacement is directly proportional to the displacement of soil particles during soil tillage. Whether the machine moves across the plane or against the slopes, the results were very similar. On the contrary, much higher transfer of particles was recorded as the machine moves downhill. From the measurements, appreciable adverse effect of machine tillage was recorded when moving downhill. Machine movement against the slope cannot be understood as a corrective step in view of tillage erosion against the movement of the machine from the slope.
\end{abstract}

Keywords: soil tillage technology; tillage erosion; soil particle translocation.

\section{Introduction}

Tillage erosion contributes to changes in soil, especially to the fertility deterioration and other of its features. Research on soil erosion during processing does not have a long history. A significant contribution to the research of tillage erosion are the works of Govers et al. [1] Li et al. [2], Muysen et al. [3]. Currently, tillage erosion of soil is considered as phenomenon that should be given special attention.

Experiments with tracers inserted into the soil in order to diagnose transfer of soil particles started at the end of the last century. Lindstrom et al. [4] used $11 \mathrm{~mm}$ size steel nuts. Li et al. [2] and other authors have used colored limestone grit (dyed limestone chips). Zhang et al. [5] considered the appropriate grit size $6-12 \mathrm{~mm}$. Larger particles $(12-25 \mathrm{~mm})$ have been proven to be better at deeper tillage, mainly due to a reduction in labor intensive collection of the tracers from the soil. Li et al. [2] point to determination of Rahman et al. [6] on inconclusive differences in the size of the tracers, or their density. Methodically similar work has been done with other reported material: crushed bricks [7]. In the literary sources as well the use of Cs-137 to detect displacement of soil particles could be found [8].

Aluminum cubes - cubes (cubes $\mathrm{Al}$ ) were used as tracers, namely Van Muysen et al. [3]- $15 \mathrm{~mm}$ edge length and also Liu et al. [8] - the length of the edges $10 \mathrm{~mm}$. Logsdon [9] gives a brief overview of tracers that gives the aluminum blocks of numbers. Also noteworthy is the work of Liu et al. [8], which in addition to displacement of soil particles during tillage evaluated displacement of straw in the soil. To detect the displacement of soil particles they used aluminum cubes with an edge length of 10 $\mathrm{mm}$.

After the positive experience with the use of colorful crushed limestone to evaluate the displacement of soil particles in soil tillage, [10] in 2016 started using metallic tracers (Aluminum cubes with an edge length of $10 \mathrm{~mm}$ ) for the evaluation of soil particle displacement in the secondary soil cultivation. A metal detector was used for position determination of the metallic tracers after tillage. 


\section{Materials and methods}

The field experiment was created in Nesperská Lhota, located in the Central Bohemia Region. The experiment was founded for the purpose of measuring displacement of soil particles in the secondary tillage technology (seedbed preparation). The land was located at an altitude of $460 \mathrm{~m}$, with light cambisol soil. The content of the particles smaller than $0.01 \mathrm{~mm}$ in the topsoil layer was : $21.3 \%$ by weight. Average measured humidity in the surface layer was $7.3 \%$ vol. (Measured with probe Theta Probe- Delta Devices). The land was processed by mounted plough after harvest of winter rape. Rough furrow was treated by levelling bars with harrows. The soil was left to rest for two weeks in order to achieve the natural dismount. There were taken intact soil samples in order to determine the soil bulk density and porosity (Kopecky cylinders with volume $100 \mathrm{~cm}^{3}$ ). The results are shown in Table 1.

Table 1

Bulk density and porosity of soil before secondary tillage

\begin{tabular}{|c|c|c|}
\hline Depth, $\mathbf{~ m}$ & Bulk density, $\mathbf{g} \cdot \mathbf{c m}^{-\mathbf{3}}$ & Porosity, \% vol. \\
\hline $0.05-0.10$ & 1.33 & 49.2 \\
\hline $0.10-0.15$ & 1.36 & 48.1 \\
\hline
\end{tabular}

The machine used for the experiments was the combinator Lemken with the working width of 6 $\mathrm{m}$. As a pulling means a tractor Zetor was used. The depth of tillage was $0.08 \mathrm{~m}$ (settings on the tines). The working speed in all variants was $4.5 \mathrm{~km} \cdot \mathrm{h}^{-1}$. The field experiment had three variants: ride on the plane, ride down the slope $\left(9.8^{\circ}\right)$ and drive against the slope $\left(8.1^{\circ}\right)$. Aluminum cubes with $12 \mathrm{~mm}$ edges were used as tracers for measuring the displacement of soil particles. 30 tracers were used for each variant. The groove for the tracers was created perpendicular to the driving direction at a depth of $0.05 \mathrm{~m}$. The width of the grooves was $1 \mathrm{~m}$. Each tracer was laid side by side in the groove. This was followed by crossing the presowing combinator. Then detection of the position of the tracers by using the metal detector was performed (Whites Devices). On the surface of the soil colored markers were placed for the location of the cubes (see Fig. 1).

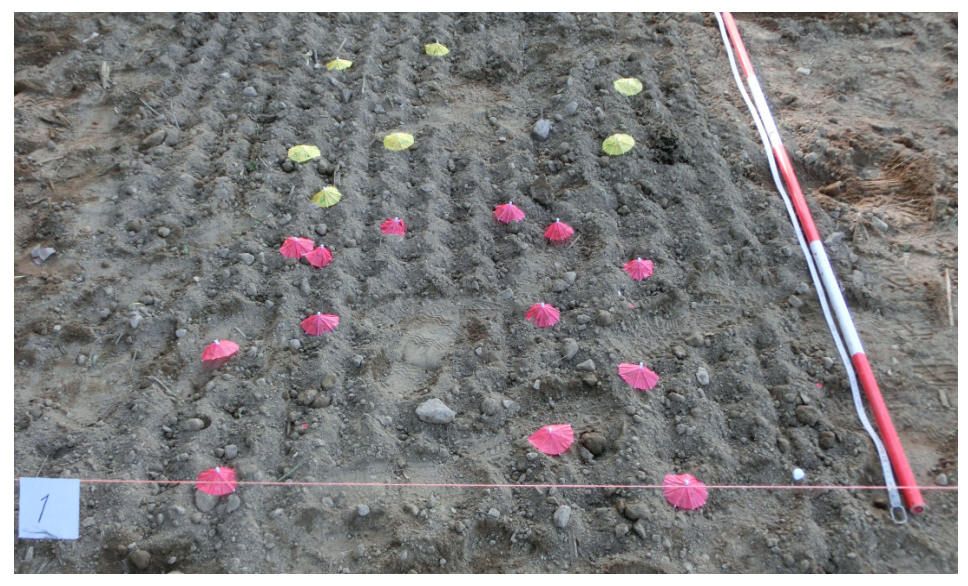

Fig. 1. Colored markers on the surface

After marking, all tracers were targeted relative to their original location. The data were subsequently analyzed using Microsoft Excel (MS Corp., USA) and Statistica 12 (Statsoft Inc., USA) software.

\section{Results and discussion}

Figure 2 represents a graph showing displacement of individual tracers for all variants. The graph shows similar displacement tracers when the machine was moving on the plane and against the slope. Only a few tracers were displaced farther away. This was probably caused by organic matter on the soil surface, which is caught between the tines. Different character of tracer translocation was recorded when moving the machine down the slope. The tracers were moved farther away. This is due to easier translocation of soil particles. The tines tend to drift downward the layer of soil. It shows that ride against the slope cannot be understood as corrective measures after the ride down the slope. 


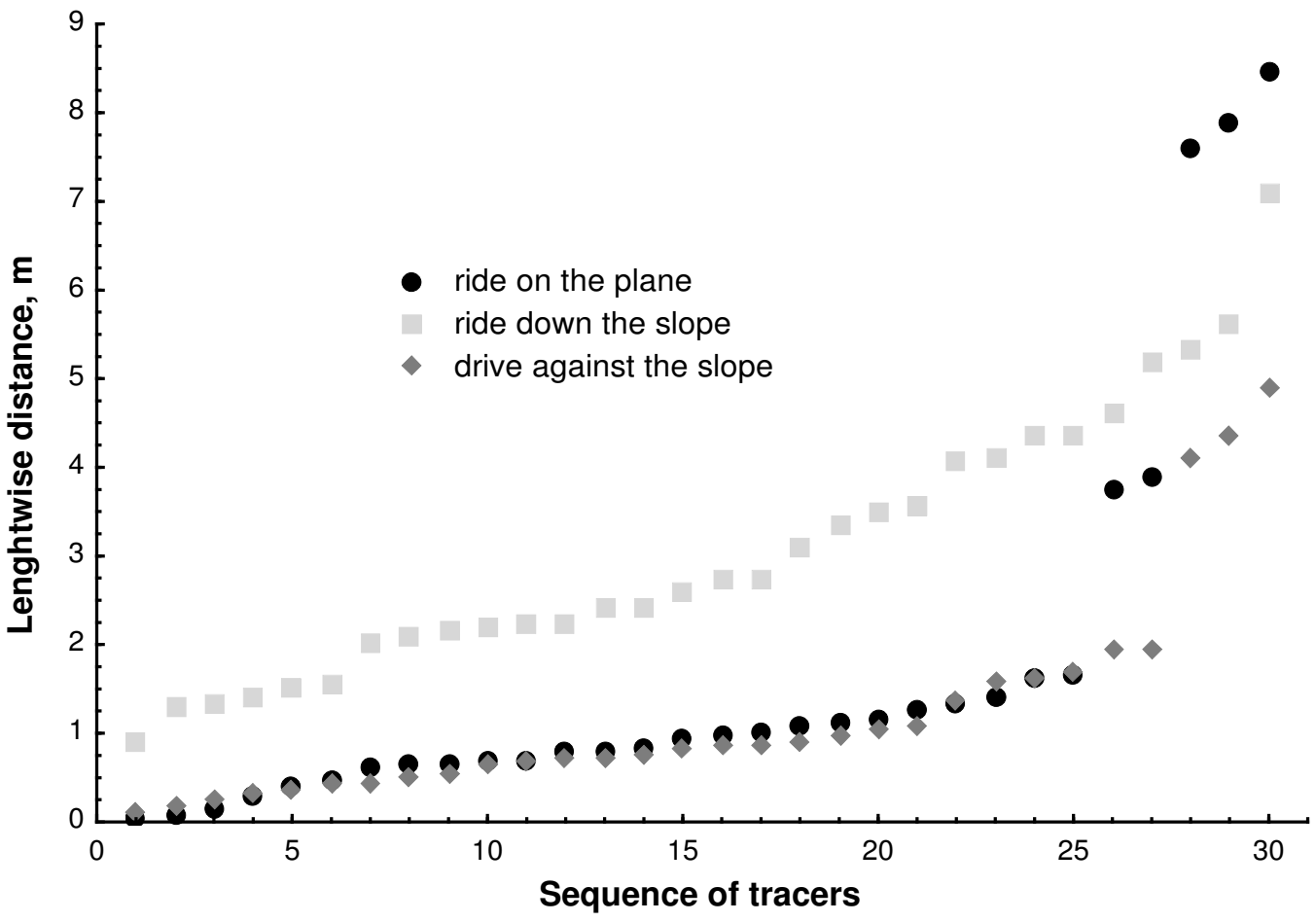

Fig. 2. Sequence of tracers for all variants

Figure 3 shows a graph of the relative frequency with respect to the distance. Relative frequency represents the percentage of all the tracers (30 pieces) in a given segment. One tracer represents $3.33 \%$. The distance is divided into one meter segments. The graph confirms the conclusions from the previous figure. A similar character of tracer translocation is noticeable during the ride on a plane and the ride against the slope. This character can be described by an exponential function, as shown in Figure 3. Most tracers have been translocated to a distance of less than $1 \mathrm{~m}$. Only a minority of the 30 tracers were translocated to a greater distance.

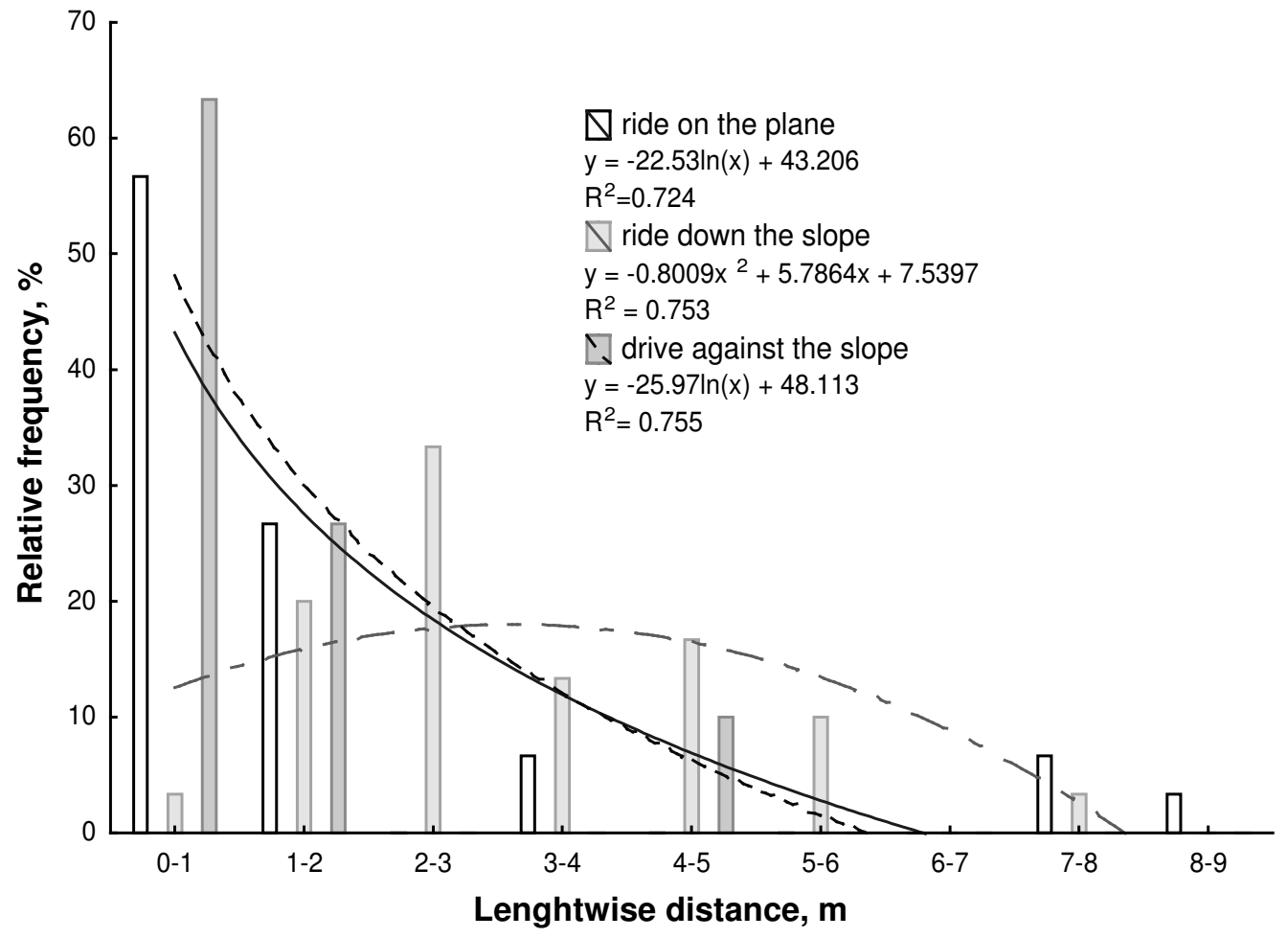

Fig. 3. Relative frequency in all segments per $1 \mathrm{~m}$ 
Completely different results are evident in the measurement of the machine movement down the slope. Mostly the tracers were recorded at a distance of 2-3 meters from the original location. Conversely, at a distance of 0-1 meters only few of the tracers were recorded. A large part of the tracers has been translocated to larger distances. The character of translocation can be described by a quadratic function.

Table 2 contains the results of the Tukey HSD test. The results show that statistically significant differences can be found between the variants. Significant differences were observed especially between the variant of the ride down the slope and the others. Homogeneous groups are identified by the letters. The test was performed at a significance level of 0.05 .

Table 2

\section{Results of Tukey HSD test}

\begin{tabular}{|c|c|c|c|}
\hline Distance, $\mathbf{m}$ & Ride on the plane & Ride down the slope & Drive against the slope \\
\hline $0-1$ & $17^{\mathrm{a}}$ & $1^{\mathrm{b}}$ & $19^{\mathrm{a}}$ \\
\hline $1-2$ & $8^{\mathrm{a}}$ & $6^{\mathrm{b}}$ & $8^{\mathrm{a}}$ \\
\hline $2-3$ & $0^{\mathrm{a}}$ & $10^{\mathrm{b}}$ & $0^{\mathrm{a}}$ \\
\hline $3-4$ & $2^{\mathrm{a}}$ & $4^{\mathrm{b}}$ & $0^{\mathrm{c}}$ \\
\hline $4-5$ & $0^{\mathrm{a}}$ & $5^{\mathrm{b}}$ & $3^{\mathrm{c}}$ \\
\hline $5-6$ & $0^{\mathrm{a}}$ & $3^{\mathrm{b}}$ & $0^{\mathrm{a}}$ \\
\hline $6-7$ & $0^{\mathrm{a}}$ & $0^{\mathrm{a}}$ & $0^{\mathrm{a}}$ \\
\hline $7-8$ & $2^{\mathrm{a}}$ & $1^{\mathrm{a}}$ & $0^{\mathrm{a}}$ \\
\hline $8-9$ & $1^{\mathrm{a}}$ & $0^{\mathrm{a}}$ & $0^{\mathrm{a}}$ \\
\hline
\end{tabular}

a,b,c,- homogenous groups - defined by Tukey HSD test

Similar studies were often conducted for primary tillage. Van Muysen et al. [3] found that the typical soil translocation during the primary soil tillage with using of mouldboard plough, chisel tiller and disc tiller is in the range between 0 and $0.9 \mathrm{~m}$ (average translocation rates). Differential effects of various tillage tools are discovered also by Hůla and Novák [11]. In their study, they emphasize the need for individual assessment of each working tool with respect to the soil conditions and operating conditions. This study describes the effect of secondary tillage in the cultivation of sloping land. Li et al. [2] regarded sloping of land as the main parameter influencing translocation of soil particles in all used technologies of soil tillage. They also showed that the ride during upslope soil tillage could not be considered as a corrective measure to the downslope movement of the machine. The same conclusion can be drawn from this study. Currently, tillage erosion is considered as a phenomenon that should be paid greater attention to.

\section{Conclusions}

The measurement results showed that:

1. Translocation of soil particles has occurred during the secondary soil tillage.

2. Translocation is affected by the slope of the land.

3. The movement of the machine on the plane and the movement against slope values showed similar results for soil translocation.

4. Considerably larger displacement was observed when machines ride down the slope.

5. Movement of machines against the slope cannot be understood as a corrective measure of movement down the slope in view of soil particle translocation.

\section{Acknowledgements}

Supported by the Ministry of Agriculture of the Czech Republic - Project no. QJ1520028 and IGA $31160 / 1312 / 3117$.

\section{References}

1. Govers G., Lobb D.A., Quine T.A. Tillage erosion and translocation: emergence of new paradigm in soil erosion research. Soil \& Tillage Research, vol. 51, 1999, pp. 167-174. 
2. Li S., Lobb D.A., Lindstrom M.J. Tillage translocation and tillage erosion in cereal-based production in Manitoba, Canada. Soil \& Tillage Research, vol. 94, 2007, pp. 164-182.

3. Van Muysen W.V., Oost K.V., Govers G. Soil translocation resulting from multiple passes of tillage under normal field operating conditions. Soil \& Tillage Research, vol. 87, 2006, pp. 218-230.

4. Lindstrom M.J., Nelson W.W. , Schumacher T.E. Quantifying tillage erosion rates due to moldboard plowing. Soil and Tillage Research, vol. 24, 1992, pp. 243-55.

5. Zhang J.H., Su Z.A., Nie X.J. An investigation of soil translocation and erosion by conservation hoeing tillage on steep lands using a magnetic tracer. Soil \& Tillage Research, vol. 105, 2009, pp. 177-183.

6. Rahman S., Lobb D.A., Chen Y. Size and density of pointtracers for use in soil translocation studies. Proceeding of the 45th Annual Meeting, Manitoba Soil Science Society. January 2002, Winnipeg, Canada.

7. Lobb D.A., Kachanoski R.G., Miller M.H. Tillage translocation and tillage erosion on shoulder slope landscape positions measured using ${ }^{137} \mathrm{Cs}$ as a tracer. Canadian Journal of Soil Science, vol. 75, 1995, pp. 211-218.

8. Liu J., Chen Y., Kushwaha R.L. Effect of tillage speed and straw length on soil and straw movement by a sweep. Soil \& Tillage Research, vol. 109, 2010, pp. 9-17.

9. Logsdon S.D. Depth dependence of chisel plow tillage erosion. Soil \& Tillage Research, vol. 128, 2013, pp.119-124.

10. Novák P., Hůla J., Kumhálová J. Translocation of soil particles at different speed of tillers. Proceedings of 6th International Conference Trends in Agricultural Engineering,September 7, 2016, Prague, CULS, pp. 433-437.

11. Hůla J., Novák P. Translocation of soil particles during primary soil tillage. Agronomy Research, vol. 14, 2016, pp. 392-399. 